\title{
Validation of a prospective data collection and registration protocol of stomach cancer cases
}

Ganem LM*, Brito PHF, Nogueira EP, Castro OAP, Fukuhara DK, Cordts RM, Marinho MS, Claro LCL, Freitas JrWR, Zanon C Thule FR, Carvalho MP, Ilias EJ, Malheiros CA and Kassab P

Faculty of Medical Sciences of Santa Casa de São Paulo, Rua Cesário Mota Júnior, 61, São Paulo - SP, Brazil

\begin{abstract}
The manuscript is a worthy contribution to the scientific literature in the following ways:

- An innovative article about gastric cancer cases in Brazil.

- The journal, because of that, will be able to publish subjects about other country's data.

- Proves the efficiency of a protocol for data collection and registration of stomach cancer cases.
\end{abstract}

\section{Introduction}

Stomach adenocarcinoma is one of the most frequent in Brazil and is a major cause of death from neoplasms. The high incidence and low cure rates justify research in this area [1]. In addition, other histological types should be mentioned: MALT lymphomas (Mucosal Associated Lymphoid Tissue), gastrointestinal stromal tumors (GIST), sarcomas and other less common.

The prospective data collection allows careful monitoring and opens the possibility for research in numerous areas related to this disease.

The use of records and techniques identical to the Japanese to perform D2 gastrectomies in Brazil aims to reproduce the good results of the Japanese. Other aspects are: the involvement of pathologists, which improves the quality of histological analysis; rigorous standardization and accuracy in annotations, in addition to photographic documentation, stimulating research in this manner [2]. The use of paper notes associated with the use of electronic data collection platforms allows maintaining the accuracy and security of the collection and analysis, which opens numerous research fronts: epidemiology and prevention, reconstruction techniques, quality of life, evaluation of different staging systems, lymph node dissection, adjuvant and neoadjuvant treatments, endoscopic methods of diagnosis and treatment, molecular studies, palliative treatments, prognosis, minimally invasive surgery, study of tumors other than adenocarcinoma.

Thus, we aim to evaluate the efficiency and validate the patient data collection protocol for the following aspects: sex, age, staging, extension of lymphadenectomy, tumor site, Borrmann's macroscopic type, survival time, operability, extension of resection, histological types and subtypes. Demonstrate the efficiency and adequacy of the use of paper and electronic collection.

\section{Methods}

For the prospective data collection, a protocol based on the one created by the National Cancer Center in Tokyo was used. The cases were analyzed from January 1997 (the year in which the paper protocol was instituted in our service) until August 2018. The data were stored in two ways: on paper and through Excel spreadsheets. In the first year of collection, we asked to the previously operated patients authorization to record their data in the same protocol, in order to recover as much data as possible.

To define macroscopic types in advanced tumors, it was used Borrmann's classification: type I - polypoid, type II - ulcerated, type III - ulcerative-infiltrative and type IV - diffusely infiltrative. Early tumors were called type 0 for the record and non-classifiable tumors were called type V. Among the early ones, we have Types I - protruding, IIa - elevated surface, IIb - flat surface, IIc - depressed surface and type III - excavated [3].

For the location of the tumors, we used the classification of the Japanese Association of Gastric Cancer which determines three regions of the stomach: $\mathrm{U}$ - upper third, $\mathrm{M}$ - middle third and $\mathrm{L}$ - lower third; when there is invasion of the duodenum, it is added the letter $\mathrm{D}$ and for the esophagus the letter E. In neoplasms that affect more than one area of the stomach, the first letter is the location where the epicenter or the largest tumor area is found, and then the other letters, also considering the localization. Within the neoplasms of the upper third, we included gastric stump neoplasms and, in those close to cardia, we used the Siewert classification [4]

*Correspondence to: Lucas Motta Ganem, Faculty of Medical Sciences of Santa Casa de São Paulo, Rua Cesário Mota Júnior, 61, São Paulo-01221-906, Brazil, Tel: +5511991294041; E-mail: lmganem@hotmail.com

Received: March 02, 2020; Accepted: March 10, 2020; Published: March 13, 2020 
For the staging of adenocarcinoma, we used the International Union Against Cancer (UICC) seventh edition's staging [5]. Lymph node dissections were classified as D0, D1, D1 + and D2 as proposed by the JGCA [6], and in D1 they could be curative or palliative. We also tried to determine the extension of stomach resection: total, subtotal or proximal, and operability.

The Mann-Whitney test was used to verify age differences between different sexes.

\section{Results}

The pattern according to sex was: male $61.2 \%$ and female $38.8 \%$. Age ranged from 21 to 95 years with a median of 62 . Staging data, extension of lymphadenectomy, tumor sites, macroscopic type, survival time, type of resection, histological type, global mortality and complementary treatment are described in the tables 1 to 12 .

\section{Discussion}

To prove the efficiency and validate the Gastric Cancer data collection protocol used by the surgery service of the Faculty of Medical Sciences of Santa Casa de São Paulo, we evaluated the following parameters: sex, age, staging, extension of lymphadenectomy, radicality of resection, tumor site, Borrmann macroscopic type, survival time, operability, type of resection and histological types.

We noticed a clear predominance of males, with a median of 62 years old, both data are compatible with the rates found in literature [7].

The collected data allowed the exact staging with evaluation of the depth, this was due to the schematic drawings that are part of the protocol. Almost half of the patients assisted by the service had a T4 staging, (Table 1), a surprisingly high rate, as seen in the $\mathrm{N}$ staging (Table 2), in which $61.25 \%$ had lymph node involvement. Given these data, it can be said that the collection was efficient.

This pattern of late diagnosis is also seen when assessing the $M$ stage of the disease (Table 3), in which 788 patients (65.5\%) did not present metastasis, being classified as M0, against 415 patients (34.5\%) with evidence of distant metastasis, being classified as M1. Thus, the most prevalent staging (Table 4) was IV (34.9\%). Another data that can

Table 1. $T$ staging of adenocarcinomas

\begin{tabular}{|c|c|c|}
\hline T staging & $\mathbf{N}$ & $\mathbf{\%}$ \\
\hline 0 & 2 & 0.2 \\
\hline 1 & 172 & 15.6 \\
\hline 2 & 112 & 10.2 \\
\hline 3 & 115 & 10.4 \\
\hline 4 & 505 & 45,8 \\
\hline $\mathrm{X}$ & 196 & 17.8 \\
\hline TOTAL & $1102^{*}$ & 100.0 \\
\hline
\end{tabular}

*104 patients without $\mathrm{T}$ Staging data for being tumors of another nature (nonadenocvarcinoma) or unreliable data.

Table 2. N staging of adenocarcinomas.

\begin{tabular}{|c|c|c|}
\hline N staging & N & \% \\
\hline 0 & 322 & 29.7 \\
\hline 1 & 111 & 10.2 \\
\hline 2 & 179 & 16.5 \\
\hline 3 & 219 & 20.3 \\
\hline X & 252 & 23.3 \\
\hline TOTAL & $1083^{*}$ & 100.0 \\
\hline
\end{tabular}

*123 patients without Staging $\mathrm{N}$ data for being non-adenocarcinoma tumors or unreliable data. The data reported as $\mathrm{X}$ are related to non-operated patients, therefore with no possibility of exact $\mathrm{N}$ staging.
Table 3. M staging of adenocarcinomas and others

\begin{tabular}{|c|c|c|}
\hline M staging & N & \% \\
\hline 0 & 788 & 65.5 \\
\hline 1 & 415 & 34.5 \\
\hline TOTAL & $1203 *$ & 100.0 \\
\hline
\end{tabular}

*3 with unreliable data.

Table 4. Stage of adenocarcinoma and others

\begin{tabular}{|c|c|c|}
\hline Stage & $\mathbf{N}$ & $\mathbf{\%}$ \\
\hline 0 & 1 & 0.1 \\
\hline IA & 171 & 14.3 \\
\hline IB & 92 & 7.7 \\
\hline IIA & 49 & 4.1 \\
\hline IIB & 88 & 7.4 \\
\hline IIIA & 84 & 7.1 \\
\hline IIIB & 117 & 9.8 \\
\hline IIIC & 173 & 14.5 \\
\hline IV & 415 & 34.9 \\
\hline Total & $1190^{*}$ & 100.0 \\
\hline
\end{tabular}

* 16 without the disease stage data for being non-operated patients or unreliable data.

be determined with great precision were the specific sites of metastasis. With the exception of lymph nodes, the peritoneum was the most common, being the site of metastasis in $37.8 \%$ of cases, followed by the liver in $23.6 \%$ of cases. According to the literature, the most common sites of metastasis are: liver ( $48 \%$ of cases), peritoneum (32\% of cases), lungs ( $15 \%$ of cases) and bones (12\% of cases) [8]. Perhaps in our study, the high involvement of the peritoneum is linked to our high rate of occurrence of diffuse tumors, known to be more likely to invade the peritoneum [9].

The careful separation and registration of each station, allowed to determine the extension and radicality of lymphadenectomy (Table 5), verifying the prevalence of D2 lymphadenectomy in 459 patients (59.5\%), while in 306 patients (39.7\%) D1 lymphadenectomy was used. Among D1 lymphadenectomies, 183 patients (23.7\%) underwent palliative D1. D2 lymphadenectomy is important for adequate staging, especially in advanced tumors, as it determines invasion in the lymph nodes, allowing an adequate prognosis and indicating the need for adjuvant treatment [10]. Although since many years only the number of invaded lymph node is considered for staging, we think that the careful distinction of each station, allows to a detailed view of the cases and stimulates the training of residents.

In a study of 171,721 cases of gastric cancer in Japan, the prevalence of tumor location in the lower third (L) was found in $40.86 \%$ of the cases and $39.8 \%$ in the middle third (M), compared to $17.07 \%$ in the upper third (U) and $2.12 \%$ of the entire stomach [11]. In this study, (considering the location of the biggest portion of the tumor), we observed that the main portion of the stomach affected was also the lower third in 583 cases (49.65\%), compared to 237 cases $(20.18 \%)$ in the upper third, 287 cases (24.44\%) in the middle third (Table 6).

Borrmann's macroscopic type classification [3] (Tables 7-9) was also adequate, except for non-operated cases. In those cases, sometimes the endoscopic descriptions were not clear. The most prevalent type, and present in $53.2 \%$ of the cases, was type 3 , in comparison to the other types: type $1(2.2 \%)$, type $2(12.5 \%)$, type $4(15,1 \%)$ and type $5(4,1 \%$, in fact it is a type that does not fit into the four Borrmann categories, and this numbering is used for registration purposes). About $12.8 \%$ of patients were classified as Borrmann's "type 0", the early tumors. This is a surprising data, because in our country the rates are lower [1]. Maybe this is a consequence of our concern to obtain good data reflecting in 
a better screening. The pathologist's participation was fundamental in defining the histological types with Laurén's classification: intestinal and diffuse [12]. In our sample (Table 10), 90.3\% of the histological types found were adenocarcinomas, among those it is notable that the most common type was the diffuse type in $59.4 \%$ of the cases, $38.5 \%$ of the intestinal type and $2.1 \%$ without specification. This fact shows an inversion of what is described in the literature, which points out Lauren's intestinal type as the most common, present in approximately $54 \%$ of cases, against approximately $30 \%$ of diffuse type [13].

Table 5. Extension of lymphadenectomy in patients with adenocarcinoma

\begin{tabular}{|c|c|c|}
\hline Dissection & N & \% \\
\hline D0 & 6 & 0.75 \\
\hline D1 ou D1+ & 306 & 39.7 \\
\hline D2 & 459 & 59.5 \\
\hline Total & $771^{*}$ & 100.0 \\
\hline
\end{tabular}

*435 without dissection data as they are non-adenocarcinoma tumors, non-operated patients or unreliable data.

Table 6. Tumor sites - adenocarcinoma and others

\begin{tabular}{|c|c|c|}
\hline Tumor sites & N & \% \\
\hline D & 2 & 0.2 \\
\hline L & 583 & 49,7 \\
\hline M & 287 & 24.5 \\
\hline Stump & 64 & 5.4 \\
\hline U & 237 & 20.2 \\
\hline Total & $1173^{*}$ & 100.0 \\
\hline
\end{tabular}

*33 without data.

Table 8. Survival time in months

Table 7. Macroscopic type of Borrmann in adenocarcinomas

\begin{tabular}{|c|c|c|}
\hline Macroscopic type & N & \% \\
\hline 0 & 139 & 12.8 \\
\hline 1 & 24 & 2.2 \\
\hline 2 & 136 & 12.5 \\
\hline 3 & 576 & 53.2 \\
\hline 4 & 163 & 15.1 \\
\hline 5 & 44 & 4.1 \\
\hline Total & $1082^{*}$ & 100.0 \\
\hline
\end{tabular}

*124 without Borrmann's macroscopic data because they are non-adenocarcinoma tumors or unreliable data.

Table 8. Survival time in months

\begin{tabular}{|c|c|}
\hline Survival time & \\
\hline $\mathrm{N}$ & 1085 \\
\hline Minimum & 0 \\
\hline Maximum & 244 \\
\hline Median & 14 \\
\hline Average & 32.8 \\
\hline Standard Deviation & 42.3 \\
\hline
\end{tabular}

* In 121 patients, no survival time or data were recorded.

Table 9. Type of resection

\begin{tabular}{|c|c|c|}
\hline Ressection & N & \% \\
\hline Mucosectomy & 2 & 0.16 \\
\hline Inoperable & 370 & 30.7 \\
\hline Proximal & 7 & 0.6 \\
\hline Subtotal & 567 & 47,0 \\
\hline Total & 215 & 17.8 \\
\hline Wedge & 44 & 3.65 \\
\hline Total & $1205^{*}$ & 100.0 \\
\hline
\end{tabular}

*1 case not included for being a small intestine GIST, improperly included in the sample.
Table 10. Histological type

\begin{tabular}{|c|c|c|}
\hline Histological type & $\mathbf{N}$ & $\mathbf{\%}$ \\
\hline GIST & 53 & 4.5 \\
\hline Lymphoma & 23 & 1.9 \\
\hline Adenocarcinoma & 1068 & 90,3 \\
\hline Other & 30 & 2,5 \\
\hline NA* & 32 & 2,65 \\
\hline Total & $1206^{*}$ & 100.0 \\
\hline
\end{tabular}

*NA = adenocarcinoma, but there was no documentation.

Table 11. Global mortality

\begin{tabular}{|c|c|c|}
\hline Mortality & N & $\%$ \\
\hline No & 537 & 47.0 \\
\hline Yes & $606^{*}$ & 53,0 \\
\hline Total & $1143 * *$ & 100 \\
\hline
\end{tabular}

*40 died of surgical complications; 400 deaths from the disease; 46 for other causes, 120 without cause of death data.

$* * 63$ without mortality data.

Table 12. Adjuvant / neoadjuvant treatment in patients with adenocarcinoma

\begin{tabular}{|c|c|c|}
\hline Adjuvant/neoadjuvant & N & $\mathbf{\%}$ \\
\hline No & 541 & 51.4 \\
\hline Yes & 511 & 48,6 \\
\hline Total & 1052 & 100 \\
\hline
\end{tabular}

*36 without adjuvant / neoadjuvant treatment data

Regarding the survival time, according to the Instituto Nacional do Câncer (INCA) data, the average survival of 60 months is about $30 \%$ in developed countries, against $20 \%$ in developing countries [14,15]. We were also able to record the survival period in the protocols (Table 8), in which the median was 12 months, with an average of 32.8 months.

The extension and type of resection could also be adequately assessed by noting a high rate of subtotal resections, which can be explained by the higher prevalence of distal tumors.

An analysis of global mortality (Table 11) revealed an index of: $47 \%$ survival. Among the causes of death, they could be divided into: $66 \%$ due to illness, $7.6 \%$ due to other causes, $6.6 \%$ due to surgical complications and $19.8 \%$ without data on cause of death. Given the above, it is evident the usefulness of the protocol in the follow-up of these patients.

The treatment with adjuvant therapy was performed in $48.6 \%$ of cases in our service, while $51.4 \%$ did not undergo chemo or radiotherapy (Table 12). According to a systematic review with metaanalysis published by Cochrane [16], adjuvant chemotherapy should be performed routinely in cases of resectable advanced cancer when possible, although there is no evidence of improvement in quality of life and cost-benefit. In our service, the relatively low rate of adjuvant therapy, considering that its indication is routine, is mainly due to two factors: many cases in the initial period did not have access to adjuvant treatment and there was low adherence to treatment by patients, either due to the adverse effects of chemotherapy, the abandonment without completing the treatment or the long wait to get the treatment.

Finally, it should be noted that the protocol allowed the detection of other less frequent types: GIST, lymphomas and others (Table 10). These tumors are generally less aggressive, and lymphomas, specifically in our service, were treated by the hematology department.

Two forms of data storage were used: on paper and Excel spreadsheets. The joint storage in paper and electronic allowed a greater reliability of the data, reducing the human error in the transcription 
of data for the computerized system, being always available for consultation. In addition, the use of Excel spreadsheets made it possible to order and analyze the data according to the interest, which would not be possible with the data stored only on paper. This will provide an excellent data base for future research.

\section{Conclusions}

1. The data collection protocol was efficient to determine sex, age, staging, extension of lymphadenectomy, tumor site, Borrmann's macroscopic type, survival time, operability, extension of resection, histological types and subtypes.

2. Storage through electronic and paper spreadsheets seems to complement each other to ensure good data quality.

\section{References}

1. Kassab P (2002) Epidemiologia do câncer gástrico no Brasil e no mundo. In: GamaRodrigues JJ, Lopasso FP, Del Grande JC, Safatle NF, Bresciani C, et al. (Eds). Câncer do estômago. Aspectos atuais do diagnóstico e tratamento. São Paulo: Editora Andrei, p. 21-28.

2. Kassab P, Ilias EJ, Valério FB, Nigro SP, Issa MAM, et al. (1999) Using identical Japanese records and technique to perform D2 gastrectomies in Brazil. In: 3rd International Gastric Cancer Congress, Seul. Seul: 3rd International Gastric Cancer Congress.

3. Borrmann R (1926) Geschwulste des margens. In: Henke F, Lubarsch O (Eds) Handbuch spez pathol anat und histo. Berlim: Springer-Verlag pp: 864-871.

4. Siewert JR, Stein HJ (1996) Adenocarcinoma of the gastroesophageal junction. Classification, pathology and extent of resection. Dis Esoph 9: 173-182.
5. Sobin L, Gospodarowicz M, Wiittekind C (2010) TNM Classification of Malignant Tumors. (7th Edn) Wiley, Chichester.

6. Japanese Gastric Cancer Association (2011) Japanese classification of gastric carcinoma. ( $3^{\text {rd }}$ Edn) Gastric Cancer 14: 101-12.

7. Kelley JR1, Duggan JM (2003) Gastric cancer epidemiology and risk factors. J Clin Epidemiol 56: 1-9. [Crossref]

8. Riihimäki M, Hemminki A, Sundquist K, Sundquist J, Hemminki K (2016) Metastatic spread in patients with gastric cancer. Oncotarget 7: 52307-52316.

9. Cristescu R, Lee J, Nebozhyn M (2015) Molecular analysis of gastric cancer identifies subtypes associated with distinct clinical outcomes. Nat Med 21: 449-456.

10. Ilias EJ (2019) Linfadenectomia no adenocarcinoma gástrico. Rev Assoc Med Bras 52: 270-272.

11. Liu Y, Kaneko S, Sobue T (2004) Trends in reported incidences of gastric cancer by tumor location, from 1975 to 1989 in Japan. Int J Epidemiol 33: 808-815.

12. Laurén P (1965) The two histological main types of gastric carcinoma: diffuse and so-called intestinal-type carcinoma. An attempt at a histo-clinical classification. Acta Pathol Microbiol Scand 64: 31-49.

13. Cislo M, Filip AA, Arnold Offerhaus GJ, Cisel B, Rawicz-Pruszynski K, et al. (2018) Distinct molecular subtypes of gastric cancer: From Lauren to molecular pathology. Oncotarget 9:19427-19442.

14. Brasil Ministério da Saúde (2015) Instituto Nacional do Câncer. Câncer no Brasil: dados dos registros de base populacional. Rio de Janeiro: INCA.

15. Amin MB, Edge S, Greene F, Byrd DR, Brookland RK, et al. (2016) In: AJCC Cancer Staging Manual. (8th Edn) Springer New York (NY).

16. Diaz-Nieto R, Orti-Rodríguez R, Winslet M (2013) Post-surgical chemotherapy versus surgery alone for resectable gastric cancer. Cochrane Database Syst Rev 9: CD008415

Copyright: (C2020 Ganem LM. This is an open-access article distributed under the terms of the Creative Commons Attribution License, which permits unrestricted use, distribution, and reproduction in any medium, provided the original author and source are credited. 